\title{
Một số gợi ý về thúc đẩy phát triển năng lực công nghệ ở Việt Nam
}

\author{
Nguyễn Hoàng Hải* \\ Cục Úng dụng và Phát triển công nghệ, Tầng 10, 113 Trần Duy Hung, Hà Nội, Việt Nam \\ Nhận ngày 12 tháng 01 năm 2017 \\ Chỉnh sửa ngày 26 tháng 02 năm 2017; Chấp nhận đăng ngày 22 tháng 3 năm 2017
}

\begin{abstract}
Tóm tắt: Năng lực công nghệ được xem như là nhân tố quan trọng hàng đầu trong quá trình thúc đẩy phát triển kinh tế và bắt kịp với các nước công nghiệp. Vì lẽ đó, chính phủ của nhiều quốc gia đang phát triển đã không ngừng nỗ lực tìm kiếm các biện pháp để thúc đẩy phát triển năng lực công nghệ. Các kinh nghiệm về phát triển năng lực công nghệ của các nước Đông Á trong quá trình thúc đẩy công nghiệp hóa đã mang đến nhiều bài học có giá trị để các quốc gia đi sau có thể tiếp thu, học hỏi. Dựa trên những kinh nghiệm từ quốc gia Đông Á, bài viết này sẽ cung cấp thêm những góc nhìn cần thiết về bản chất và các yêu cầu cần quan tâm về phát triển năng lực công nghệ đối với các nước đang nỗ lực bắt kịp các quốc gia công nghiệp đi trước về công nghệ như Việt Nam hay các nước đang phát triển nói chung.

Tù khóa: Công nghệ, Năng lực công nghệ, Phát triển năng lực công nghệ, chính sách phát triển năng lực công nghệ.
\end{abstract}

\section{Khái niệm}

Công nghệ là giải pháp, quy trình, bí quyết kỹ thuật, phương tiện dùng để biến đổi nguồn lực thành sản phẩm. Công nghệ vừa là thành tựu, vừa là công cụ quan trọng bậc nhất của sự phát triển, trở thành thước đo của sự văn minh, khiến cho xã hội thời sau khác biệt với xã hội thời trước về chất, về cách thức tạo ra của cải vật chất cho xã hội. Những thừa nhận về vị thế của công nghệ đối với phát triển đã dẫn bước cho các nhà nghiên cứu tiếp tục đi sâu vào tìm kiếm các cơ chế, cách thức mà công nghệ có thể ảnh hưởng, tác động đến quá trình phát triển của một quốc gia, đặc biệt ở các nước đang phát triển mong muốn bắt kịp với các nước công

\footnotetext{
* ĐT.: 84-982907776

Email: hainguyen_mti@yahoo.com
}

nghiệp hóa đi trước. Đi theo hướng nghiên cứu này, khái niệm "Năng lực công nghệ" (Technological Capability) đã dần được định hình và thừa nhận trong các nghiên cứu của nhiều quốc gia. Các báo cáo của $\mathrm{UNIDO}^{1}$ đã khẳng định năng lực công nghệ (NLCN) là một tác nhân thiết yếu trong quá trình phát triển kinh tế và sự phát triển công nghiệp của một quốc gia lệ thuộc vào khả năng của các doanh nghiệp trong việc phát triển và bảo đảm năng lực công nghệ và duy trì khả năng cạnh tranh.

Mặc dù thuật ngữ "Năng lực công nghệ" dù được đề cập đến như là một nền tảng quan trọng trong phát triển công nghiệp, kinh tế của các quốc gia nhưng do năng lực công nghệ (NLCN) có sự gắn kết chặt chẽ với tính chất và đặc thù của từng ngành, từng lĩnh vực (sản xuất,

\footnotetext{
${ }^{1}$ Các năm 2002, 2004
} 
dịch vụ) nên dẫn đến chưa việc diễn giải đầy đủ về quy mô và tính chất của loại năng lực này vẫn còn chưa có sự thống nhất.

Tổ chức Lao động thế giới (ILO, 1986) [1] định nghĩa NLCN: "khả năng của một đất nước trong việc lựa chọn, tiếp nhận, tạo ra và ưng dụng các công nghệ để đóng góp vào việc đạt được các muc tiêu phát triển quốc gia”.

Một nghiên cứu của Sharif [2] phân định NLCN gồm: Năng lực tiếp nhận (Acquiring): Tiếp nhận các nguồn lực đầu vào thiết yếu cho doanh nghiệp; Năng lực chuyển hóa (Converting): Chuyển dịch các nguồn lực đầu vào sẵn có thành các sản phẩm thị trường; Năng lực giao thương (Vending): bố trí phân bổ, bán hàng và các dịch vụ đối với sản phẩm tạo ra; Năng lực hiệu chỉnh (Modifying): Thích nghi và cải tiến sản phẩm và quy trình; Năng lực thiết kế (Designing): Chuyển hóa các ý tưởng thành các vật mẫu có thể sản xuất được; Năng lực làm mới (Generating): Thương mại hóa được máy móc và quy trình mới.

Lall [3] trong nghiên cứu về năng lực công nghệ và quá trình công nghiệp hóa của các nước Đông Á đã kết luận rằng NLCN tổng hợp các kỹ năng, kinh nghiệm và nỗ lực để các doanh nghiệp của một quốc gia có thể tiếp cận, mua, sủ dụng, thích nghi, cải tiến và tạo ra công nghệ.

Dù chưa có sự thống nhất như vậy nhưng xem xét trong các diễn giải và mô tả, có thể nhận thấy quá trình phát triển NLCN đều có chung những đặc điểm sau:

Thứ nhất, NLCN là một quá trình học hỏi và tích lũy. Học hỏi công nghệ (technological learning) có thể được hiểu là quá trình mà qua đó cho phép các doanh nghiệp, ngành công nghiệp và quốc gia có thể tích lũy được các năng lực cho bản thân để thực hiện các hoạt động đổi mới về mức độ và loại hình khác nhau liên quan đến quá trình sản xuất. Ernst và cs [4] đã nhận dạng 03 loại hình học hỏi công nghệ là học hỏi chính tắc (formal learning) để nhận chứng chỉ, bằng cấp chuyên môn, học hỏi phi chinh tắc (non-formal learning) thông qua quá trình làm việc, thực hành trên máy móc, hợp tác, liên kết với các đối tác, và học hỏi gián tiếp (informal learing) dựa trên tiếp nhận các kỹ năng, kinh nghiệm từ việc tiếp nhận nhân lực, hợp tác với các doanh nghiệp tương tự ở nước ngoài hoặc các công ty đa quốc gia. Lall (trích từ [5]) cụ thể hóa thành 03 loại hình học hỏi là i) hoc hỏi căn bản (Elementary learning) gồm hoc thông qua thục hành (Learning by doing) và hoc qua thich nghi (Learning by adapting); ii) học hỏi trên căn bản (Intermediate learning) gồm học thông qua thiết kế (learning by designing) và học thông qua cải tiến thiết kế (learning by improved design); iii) hoc hỏi cấp cao (Advanced learning) gồm họ hoi thông qua thiết lập hệ thống sản xuát hoàn chỉnh (learning by setting up a complete production system).

Thứ hai, việc xây dựng năng lực công nghệ phải xuất phát từ khu vực doanh nghiệp. Đây là lực lượng trung tâm, chủ chốt trong mọi nỗ lực nhằm phát triển năng lực công nghệ của một ngành hay một quốc gia. Quan điểm này được kể thừa từ Schumpeter khi bàn về đổi mới và phát triển kinh tế. Theo Schumpeter và các nghiên cứu đi theo quan điểm này, sự phát triển về kinh tế của các quốc gia dựa trên nền tảng tiến hóa của công nghệ - công nghiệp. Qua mỗi giai đoạn phát triển công nghệ - công nghiệp, thế giới lại vươn lên một tầng cao mới về sự văn minh, hiện đại. Quan trọng hơn, động lực để tạo lập những công cuộc thay đồi lớn như vậy lại xuất phát từ những đổi mới mang tính tiệm tiến, từng bước (incremental innovation), tiển tới những đổi mới mang tính căn bản (radical innovation) về sản phẩm và quy trình của các doanh nghiệp trong các ngành công nghiệp ở các quốc gia. Cho đến nay, quy luật tiến hóa này vẫn đang được vận hành theo đúng quỹ đạo vốn có.

Thứ ba, dù doanh nghiệp là trung tâm của các hoạt động xây dựng năng lực công nghệ nhưng để bảo đảm cho các nỗ lực của doanh nghiệp trong một ngành, một quốc gia được thực hiện một cách "hoàn hảo nhất" trong các điều kiện biến động khách quan của quy luật thị trường, nhất thiết phải có sự tham gia, can thiệp của chính phủ. Chính phủ không tham gia trực tiếp vào các nỗ lực của doanh nghiệp nhưng 
đóng vai trò là điều kiện đủ để bảo đảm NLCN của doanh nghiệp có thể được phát triển và đóng góp vào phát triển chung của quốc gia. Ở một phương diện khác, việc chính phủ có thể bảo đảm các điều kiện cần cho phát triển NLCN của doanh nghiệp cũng được xem chính là một dạng năng lực đóng góp vào phát triển NLCN quôc gia. Điều này đặc biệt quan trọng ở các nước đang phát triển đặt mục tiêu bắt kịp các nước đi trước nhưng chưa có đủ các thiết chế và quy tắc tối ưu cho một nền kinh tế thị trường [6]. Đây cũng chính là cơ sở quan trọng để nồi lên các quan tâm và đề xuất về sự cần thiết phải thiết kế các chính sách thúc đẩy phát triển năng lực công nghệ trong các ngành công nghiệp hoặc ở quy mô quốc gia như Lall [7], Kim [8], Dasgupta $[9], \ldots$. đề cập trong các nghiên cứu của mình.

Như vậy, nếu như không quá chú trọng vào bản chất của NLCN hiện vẫn còn đang được tiếp tục khai phá, việc phát triển NLCN có thể được xem là quá trình học hỏi, tích lũy các kinh nghiệm, tri thức, kỹ năng về công nghệ để nâng cao năng suất, chất lượng và khả năng cạnh tranh của sản phẩm, hàng hóa của doanh nghiệp, của ngành và của quốc gia. Sự tham gia, can thiệp bằng chính sách và đầu tư của chính phủ đối với các nỗ lực phát triển NLCN là để giúp cho quá trình học hỏi được thuận lợi, giảm bớt các chi phí giao dịch (transaction cost) chứ không làm thay đổi bản chất của thị trường tự do.

\section{Các phương cách phát triển năng lực công nghệ: kinh nghiệm các nước Đông Á}

Để nhận dạng được đầy đủ hơn về các cách thức phát triển năng lực công nghệ trong doanh nghiệp ở cấp độ quốc gia, cũng đã có những nghiên cứu về kinh nghiệm của các nước công nghiệp phát triển phương Tây, nhưng có lẽ dấu ân tác động của năng lực công nghệ đối với phát triển công nghiệp tại các quốc gia Đông Á (Nhật Bản, Hàn Quốc, Đài Loan, Singapore) trong quá trình bắt kịp các nước công nghiệp hóa đi trước là được thể hiện rõ nét, cung cấp nhiều luận cứ quan trọng để khẳng định vai trò và tầm quan trọng của việc phát triển năng lực công nghệ. Xem xét các công trình nghiên cứu của Lall [7, 10], Westphal [11], Bell và Pavitt $[12,13] \ldots$ các những nhận định, đánh giá hay phát hiện về phương thức thúc đẩy phát triển năng lực công nghệ đã được tìm thấy thông qua những nỗ lực phát triển công nghệ ở các quốc gia công nghiệp mới Đông Á này. Trong quá trình thúc đẩy công nghiệp hóa giai đoạn 19601990, các quốc gia này đều đã ít nhiều trải qua các thời điểm tập trung nguồn lực và nỗ lực chính sách để triển khai các phương thức phát triển năng lực công nghệ như sau:

\section{a) Đi ngược vòng đời sản phẩm (đi tù OEM tới $O D M$ tói $O B M^{3}$ )}

Theo cách này, các doanh nghiệp bản địa bắt đầu bằng cách: trước tiên là tham gia vào hợp đồng phụ thành phần đơn giản hoặc hợp đồng lắp ráp, điển hình dựa trên phương thức sản xuất theo thiết bi nguyên gốc (OEM), sau đó từng bước di chuyển ngược dòng để đi lên mức độ sản xuất tinh xảo hơn là sản xuất dựa trên thiết kế gốc (ODM) để bán trực tiếp người mua cuối cùng, và cuối cùng ở cấp độ cao nhất là tự phát triển sản phẩm của mình và bán dưới thương hiệu riêng của mình, tức là sản xuất theo thương hiệu riêng (OBM).

Cách tiếp cận này là điển hình của các công ty công nghệ thông tin (IT) người Đài Loan mà bắt đầu bằng cách bắt chước máy tính cá nhân (PC) hay sản xuất các phần chính của hệ thống công nghệ thông tin. Điểm nhấn mạnh quan trọng trong chiến lược này là sử dụng kinh nghiệm cung cấp cho khách hàng cao cấp như một cách thức để học hỏi về công nghệ sản phẩm cũng như công việc kinh doanh có liên quan về sau. Việc dịch chuyển từ sản xuất theo nguyên mẫu đến sản xuất theo thiết kế thường được thực hiện dựa trên phản hồi từ các nhà cung ứng cho hoạt động sản xuất chia sẻ thông tin về nhu cầu, yều cầu của người mua để từ đó

\footnotetext{
${ }^{2}$ Reverse Product- Life-Cycle

${ }^{3}$ OEM: Original Equipment Manufacturing; ODM: Orgininal Design Manufacturing; OBM: Own -Brand Manufacturing.
} 
bảo đảm rằng sản phẩm được thiết kế đó có thể được sản xuât hay không.

Tính khả thi của phương thức "đi ngược vòng đời sản phẩm" căn bản phụ thuộc vào sự sẵn có và sự thiện chí của người mua đối với việc đặt hàng các hợp đồng sản xuất dựa trên nhượng quyền sử dụng thiết kế của họ. Ví dụ, việc gia nhập thành công của các doanh nghiệp Hàn Quốc vào ngành công nghiệp chế tạo vi mạch bán dẫn trong những năm đầu 1980 một phần là do tại thời điểm đó, có một số doanh nghiệp thiết kế chip Mỹ gặp phải khó khăn về tài chính nên phải nhượng quyền sử dụng các thiết kế chíp. Sự thành công nhanh chóng của các doanh nghiệp Hàn Quốc trong việc thiết kế chip dẫn đến việc các nhà thiết kế chip đã hạn chế dần sự chuyển giao. Nhưng như thế là quá đủ, người Hàn Quốc đã kịp học hỏi để phát triển thiết kế riêng của họ, đến đầu những năm 1990, họ bắt kịp công nghệ và có đủ năng lực sản xuất theo thương hiệu riêng DRAM 64MB.

Bảng 1. Quá trình bắt kịp trong công nghệ chế tạo DRAM của Hàn Quốc

\begin{tabular}{lllllll}
\hline & 64K DRAM & $\begin{array}{l}\text { 256K } \\
\text { DRAM }\end{array}$ & 1M DRAM & 4M DRAM & 16M DRAM & 64M DRAM \\
\hline $\begin{array}{l}\text { Các nước } \\
\text { phát triển }\end{array}$ & 1979 & 1982 & 1985 & Cuối 1987 & Đầu 1990 & Cuối 1992 \\
$\begin{array}{l}\text { Hàn Quốc } \\
\begin{array}{l}\text { Khoảng } \\
\text { cách }\end{array}\end{array}$ & 1983 & 1984 & 1986 & Đầu 1988 & Giữa 1990 & Cuối 1992 \\
\hline
\end{tabular}

Nguồn: The Ministry of Trade, Industry and Energy [14]

\section{b) Xây dựng lộ trình bắt kịp nhanh}

Một biến thể quan trọng của chiến lược "đi ngược vòng đời sản phẩm” trên là dành cho các doanh nghiệp bản địa có thể trở thành những người bắt kịp nhanh chóng trên các thị trường sản phẩm. Các doanh nghiệp bắt đầu bằng cách sản xuất các sản phẩm đã ở mức tới hạn ${ }^{4}$ bão hòa trên thị trường, hoặc theo giấy phép công nghệ từ các doanh nghiệp trong các quốc gia tiên tiến, hoặc thông qua học tập bắt chước nếu các công nghệ có liên quan không bị bảo hộ độc quyền. Các sản phẩm ban đầu có xu hướng được dựa trên các công nghệ thế hệ mới nhất và thường nhắm vào phân khúc thị trường giá thấp. Lộ trình thâm nhập này cho phép các doanh nghiệp để tận dụng lợi thế chi phí ban đầu thấp hơn để tiếp nhận thị trường các sản phẩm cấp thấp từ các doanh nghiệp dẫn dắt thị trường. Dựa trên khả năng làm chủ công nghệ quy trình và công nghệ sản phẩm đã tương đối hoàn chỉnh, các doanh nghiệp tìm cách chuyển

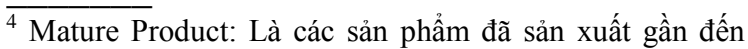
điểm bão hòa về nhu cầu, chuẩn bị nhường cho các sản phẩm mới hơn.
}

sang làm các sản phẩm với sự tinh tế cao hơn dựa trên các công nghệ tiên phong hơn. Theo thời gian, bằng cách đầu tư nhiều hơn cho học hỏi và thực hiện theo sự hướng dẫn của doanh nghiệp dần dắt công nghệ thông qua mô phỏng nghiên và phát triển, phát triển sản phẩm, các doanh nghiệp đi sau sẽ tìm ra được thời cơ để thu hẹp hoặc xóa mờ khoảng cách công nghệ giữa họ và các doanh nghiệp đi tiên phong về công nghệ, đây là cách bắt kịp nhanh.

Chiến lược này có điểm khác biệt với phương thức OEM - ODM - OBM, các doanh nghiệp theo đuổi lộ trình học hỏi này cạnh tranh trực tiếp trên thị trường người tiêu dùng cuối cùng, mặc dù bắt đầu tại điểm cuối cùng giá rẻ. Vì vậy, sự thực hiện phương cách này cần phải được bổ sung bằng việc đầu tư cùng lúc trong tiếp thị và phát triển thương hiệu. Cụ thể là theo thời gian, các doanh nghiệp cần chuyển đổi hình ảnh từ một nhà sản xuất cấp thấp, công nghệ lạc hậu thành nhà sản xuất có độ tinh xảo có chất lượng cao và sử dụng công nghệ tiên tiến, đây thường là một nhiệm vụ khó khăn, đặc biệt là cho các sản phẩm tiêu dùng đại chúng. Khi chúng di chuyển gần hơn tới các sản phẩm 
hàng đầu, chúng sẽ ngày càng được coi là mối đe dọa cạnh tranh bởi các doanh nghiệp thống lĩnh thị trường lớn, do vậy, việc cấp phép công nghệ sẽ ngày càng trở nên không dễ dàng, buộc các doanh nghiệp này đầu tư đáng kể hơn trong sản phẩm của mình và quá trình nghiên cứu và phát triển.

\section{c) Tập trung chuyên sâu về năng lực sản xuất}

Thay vì tìm cách để chuyển vào đổi mới sản phẩm OBM, với những rủi ro hơn đi kèm của quá trình sản xuất và phát triển năng lực tiếp thị của mình ${ }^{5}$, một số doanh nghiệp đã chọn để tập trung lực lượng và các nguồn lực của họ để trở thành các chuyên gia trong sản xuất cho doanh nghiệp khác. Điều này được thể hiện dưới hình thức các hợp đồng lắp ráp chuyên môn, dựa trên năng lực cốt lõi trong vận hành quy trình và đổi mới quy trình, cho phép các doanh nghiệp dịch chuyển lên vị thế cao về trình độ sản xuất chuyên sâu, luôn luôn ở mức chi phí thấp nhất hoặc chất lượng cao nhất. Một biến thể khác của phương cách này là doanh nghiệp tập trung vào việc cung cấp các linh kiện, thiết bị cho thị trường chuyên sâu riêng hoặc thực hiện một số quy trình sản xuất nhất định. Nhiều doanh nghiệp từ Singapore, đã cơ bản bắt đầu với vị trí là nhà thầu phụ và các nhà sản xuất theo hợp đồng cho các công ty đa quốc gia đẳng cấp thế giới, là những đại diện đi theo chiến lược này.

Để theo đuổi chiến lược này, các doanh nghiệp cần tập trung các nguồn lực vào không ngừng cải thiện hiệu quả hoạt động của họ, hoặc là thông qua quá trình nghiên cứu và phát triển, hoặc bằng cách mua lại các công nghệ mới nhất và đưa vào sản xuất càng sớm càng tốt để gặt hái lợi thế người đi đầu trong những người cùng hướng đi. Bên cạnh việc giữ liên lạc chặt chẽ với các nhà cung cấp công nghệ hàng đầu, các doanh nghiệp cũng cần phải giữ liên

\footnotetext{
$\overline{5}$ Điều này có thể đòi hỏi doanh nghiệp phải quan tâm đồng thời cả về chất lượng, hiệu quả sản xuất, lẫn việc cung cấp các quan điểm chiến lược về sản phẩm, công nghệ mới, về phát triển thương hiệu tới toàn bộ hệ thống sản xuất, kinh doanh để hướng dần đến việc ít bị lệ thuộc hơn vào các doanh nghiệp dẫn dắt đi trước.
}

lạc chặt chẽ với khách hàng để dự đoán yêu cầu quá trình trong tương lai. Cuối cùng, các công ty sẽ cần phải đầu tư một lượng vốn ngày càng tăng trong quá trình nghiên cứu và phát triển để tiếp cận các công nghệ tiên tiến hơn.

\section{d) Phát triển công nghệ tiên phong và đổi mới sản phẩm}

Một số doanh nghiệp từ các nước công nghiệp mới Đông Á đã chọn chiến lược nhiều khó khăn hơn để trở thành người tiên phong trong công nghệ hoặc nhà sáng tạo sản phẩm trên thị trường toàn cầu. Chiến lược này khó khăn hơn cho các nước công nghiệp mới bởi vì, như đã chỉ ra trước đó, họ cần phải vượt qua hai bất lợi cố hữu so với các doanh nghiệp từ các nước công nghiệp: thứ nhất là xa các thị trường tiêu dùng hàng đầu hơn, vì các thị trường tiêu dùng này thường định vị tại các quốc gia tiên tiến nhất; và thứ hai, họ cũng xa các nguồn cấp về tri thức, thông tin khoa học và công nghệ, đây cũng là thứ mà theo xu hướng cũng được đặt tại các nước tiên tiến.

Để khắc phục các bất lợi này, các doanh nghiệp Đông Á đã thành công trong việc trở thành những người tiên phong trong công nghệ dựa các cách đi sau đây:

Thứ nhất, để thiết lập một sự hiện diện mạnh mẽ, mặc dù chi phí lớn, trong thị trường tiêu dùng hàng đầu để theo đuổi công nghệ sản phẩm hoặc phát triển kênh phân phối thị trường, trong khi khai thác các nguồn hỗ trợ trên nền tảng trong nước. Điều này đòi hỏi những nỗ lực kinh doanh phi thường hoặc nhận được sự ủng hộ của các tập đoàn tài chính mạnh với tầm nhìn dài hạn và vốn lớn. Một phần quan trọng của chiến lược này là đầu tư mạnh vào phát triển thương hiệu thông qua phát triển kênh quảng cáo và tiếp thị, điều này thường tốn nhiều thời gian để nhận được kết quả.

Thứ hai là đầu tư vào, hoặc sở hữu được, các doanh nghiệp khởi nghiệm công nghệ cao tiềm năng ở các nước tiên tiến. Nỗ lực này chứa đựng nhiều rủi ro bởi vì các doanh nghiệp Đông Á thường thiếu khả năng để đánh giá các khoản đầu tư như vậy, cho rằng có rất nhiều tài sản của các công ty đó là các tài sản vô hình, được 
ẩn chứa trong những người sáng lập và có thể dễ dàng bị mất thông qua việc di chuyển của các nhân sự chủ chốt. Tuy nhiên, cánh cửa cơ hội thành công vẫn có thể để mở ra bất kỳ lúc nào đối với những nỗ lực đầu tư vào doanh nghiệp khởi nghiệp công nghệ cao hay việc mua lại các doanh nghiệp ở các nước tiên tiến.

Cách tiếp cận thứ ba là thu hút nhân sự có trình độ cao, có thể nắm giữ các bí quyết công nghệ tiên tiến làm việc, thông qua tài trợ vốn liên doanh, các khoản trợ cấp để bắt đầu hoạt động, hoặc bổ nhiệm vào vị trí lãnh đạo trong các viện nghiên cứu địa phương. Cụ thể như công ty Đài Loan và Hàn Quốc đã nhắm mục tiêu những người được đào tạo và có kinh nghiệm làm việc tại Mỹ, trong khi các công ty Singapore đang cố gắng khai thác người di cu từ Trung Quốc và Ân Độ.

Cuối cùng, nhưng không kém phần quan trọng là tạo điều kiện cho các doanh nghiệp tham gia vào hoạt động nghiên cứu và phát triển hoặc phối hợp với các cơ sở nghiên cứu, trường đại học, các doanh nghiệp địa phương khác hoặc các công ty nước ngoài, để có thể tự phát triển được công nghệ tiên phong vượt qua các công ty đối thủ cạnh tranh ở các nước tiên tiến. Để bù đắp những lợi thế mà các công ty từ các nước tiên tiến có thể có, các doanh nghiệp trong nước phải được tạo điều kiện cũng như là hỗ trợ để có thể tiếp cận được nhân lực nghiên cứu và phát triển với chi phí rẻ, phát huy được lợi thế cạnh tranh quốc gia (hoặc theo vùng), các nguồn lực hỗ trợ của chính phủ trong giai đoạn đầu (tài trợ cho nghiên cứu và phát triển, hỗ trợ tín dụng, chuyển giao công nghệ từ các viện nghiên cứu công, bảo hộ thị trường tiềm năng trong nước, cơ chế mua sắm công của chính phủ), đặc biệt là các cơ hội có thể tạo nên những đột phá về công nghệ, để mở ra những thị trường mới, vị thế dẫn dắt mới trên thị trường quốc tế.

Một biến thể của phương cách này là nhận diện vị thế về nghiên cứu và phát triển ở các nước trong khu vực có nhiều nhân lực nghiên cứu nhưng thiếu cơ sở hạ tầng để thương mại hóa sản phẩm (ví dụ như Trung Quốc, Ân Độ và Nga). Trong trường hợp này, các doanh nghiệp Đông Á đã tận dụng tối đa lợi thế cạnh tranh về sư gần gũi về mặt địa lý/ văn hóa hay các mạng lưới liên lạc kinh doanh đã được thành lập trước đó để thu hút được nhân lực và công nghệ có chất lượng từ các quốc gia như vậy.

\section{đ) Hướng vào đi truớc trong các úng dụng}

Theo phương cách này, một tổ chức, doanh nghiệp sẽ hướng sự quan tâm, nguồn lực để phát triển trở thành một nhà sáng tạo, không phải dựa vào công nghệ sản xuất mới mà trong việc áp dụng công nghệ hiện có theo những cách sáng tạo mới.

Sự thành công của cách tiếp cận này xoay quanh cách thức doanh nghiệp ứng dụng một cách sáng tạo với công nghệ mới sẵn có, chứ không phải dựa trên việc phải sáng tạo của các công nghệ mới hoàn toàn. Các doanh nghiệp thực hiện phương thức này phải có hiểu biết tốt về kinh doanh và các vấn đề cạnh tranh, theo đó các công nghệ mới có thể được điều chỉnh để cải thiện khả năng cạnh tranh tốt nhất cho công ty trong ngành kinh doanh đã chọn. "Sự hợp nhất" này của bí quyết kinh doanh và công nghệ, về mặt hiệu quả, liên quan đến việc tạo ra các năng lực tiến bộ hơn.

Về tổng thể năm phương cách phát triển năng lực công nghệ không loại trừ lẫn nhau, nhưng đại diện cho các hướng chiến lược quan trọng của phát triển năng lực cạnh tranh của doanh nghiệp của các nước công nghiệp mới Đông Á từ những năm 1960 đến nay. Về vận dụng các phương cách này, nhìn chung, các công ty từ Singapore xuất hiện để nhấn mạnh chuyên môn hóa quá trình và việc tiên phong trong các ứng dụng, mặc dù các cách khác cũng đang trở nên quan trọng. Với sự phát triển của các Chaebol (hình thái kinh doanh tập đoàn), Hàn Quốc nhấn mạnh vào chiến lược đi ngược vòng đời sản phẩm và các chiến lược "bắt kịp nhanh", đặc biệt tập trung vào các lĩnh vực mà các nền kinh tế quy mô lớn cho là quan trọng. Tới những năm cuối 1990 , việc tiên phong về công nghệ sản phẩm đã bắt đầu được các Chaebol Hàn Quốc theo đuổi. Trong khi đó Đài Loan, với số lượng lớn của các doanh nghiệp vừa và nhỏ (SMEs), chủ yếu là theo đuổi học 
hỏi quá trình đi ngược vòng sản phẩm và lộ trình bắt kịp nhanh, tập trung đặc biệt vào các lĩnh vực thiết kế chuyên sâu như máy tính cá nhân (PC) và các thiết bị ngoại vi, các công cụ máy móc, và các sản phẩm cơ khí có độ chính xác cao. Các quan tâm để thực hiện chiến lược đi tiên phong trong công nghệ sản phẩm và tập chung chuyên môn sâu cũng đã được các doanh nghiệp Đài Loan tập trung và phát triển năng lực.

\section{Các tác nhân ảnh hưởng đến phát triển năng lực công nghệ}

Năng lực công nghệ của doanh nghiệp, của quốc gia không phải được tạo lập một cách tự nhiên, mà phải qua một quá trình "tiến hóa". Việc phát triển chúng đòi hỏi những nỗ lực có chủ ý và lâu dài của doanh nghiệp và chính phủ trong việc học hỏi, tích lũy và phát triển các tri thức công nghệ. Để có thể triển khai được các phương cách phát triển năng lực công nghệ như nêu ở trên, điều kiện đủ cần phải lưu ý là:

\section{Thư nhất, hạ tầng và điều kiện nền tảng.}

Đây được xem là nhân tố cứng cho mọi nền kinh tế - công nghiệp của một quốc gia. Khả năng tạo lập được năng lực công nghệ nhanh hay chậm dựa vào sự sẵn có và sẵn sàng của các nhân tố này, bao gồm: đầu tư, nguồn nhân lực và nỗ lực công nghệ. Sự sẵn có về phương diện đầu tư được hiểu là những nền tảng hạ tầng kỹ thuật (như nhà máy, thiết bị, công nghệ, hệ thống giao thông, CNTT,...) để phục vụ cho hoạt động của một hay nhiều ngành công nghiệp được chính phủ ưu tiên. Với chuẩn bị tốt về hạ tầng, hay nói cách khác là sự quyết tâm của chính phủ trong các mục tiêu đầu tư cho phát triển công nghiệp thì nhu cầu xây dựng và phát triển năng lực công nghệ mới được phát sinh và quan tâm đúng mức.

Khía cạnh nhân lực phản ánh khả năng cung ứng nguồn nhân lực có kỹ năng và có trình độ cho các hoạt động công nghiệp của nền kinh tế. Điều này hàm chứa tầm quan trọng của chất lượng của hệ thống giáo dục chính quy và hệ thống đào tạo nghề cũng như là chất lượng đào tạo, giáo dục của khu vực công và khu vực tư trong một quốc gia. Kinh nghiệm các nước công nghiệp hóa đi trước cho thấy, hệ thống giáo dục chính quy nếu có chất lượng tốt sẽ cung cấp nguồn nhân lực chất lượng cao, đặc biệt là các chuyên gia, kỹ sư về công nghệ giúp cho việc xây dựng năng lực công nghệ trở nên dễ dàng hơn. Điều này thường được thể hiện trong cơ cấu sinh viên tốt nghiệp trong các lĩnh vực thiên về khoa học kỹ thuật hơn là các ngành khoa học xã hội. Đào tạo chính quy cũng phải đồng thời với hệ thống đào tạo nghề bởi vì các hoạt động công nghiệp không chỉ cần những khối óc và còn cần cả những đôi tay, những người thợ lành nghề. Ở một chừng mực nào đó, trước khi một hệ thống công nghiệp trong nước có thể thực hiện các thay đổi lớn, dựa trên năng lực của đội ngũ kỹ sư, chuyên gia công nghệ, thì cũng vẫn luôn phát sinh những thay đổi nhỏ, hay những cải tiến, điều này thường được tạo ra từ những nỗ lực thực hành thường xuyên trên máy móc, thiết bị. Đây chính là vai trò của những người lao động lành nghề.

Khía cạnh tiếp theo đó là các nỗ lực có chủ ý về công nghệ trong các hoạt động công nghiệp. Dù hạ tầng công nghiệp có tốt, nhân lực có trình độ cao và lành nghề nhưng nếu như không có các tác động, điều chỉnh có chủ ý từ phía Chính phủ về các ưu tiên phát triển công nghệ thì việc xây dựng năng lực công nghệ hay cao hơn là tự chủ công nghệ sẽ là một mục tiêu khó thực hiện. Trong trường hợp này, Chính phủ phải có những sách lược và khoản đầu tư để có thể nhanh chóng tiếp cận, thích nghi và làm chủ được công nghệ trong một số khâu của hoạt động công nghiệp. Cách đi của chính phủ có thể dựa vào khả năng nội sinh của quốc gia hoặc có thể dựa trên quá trình giải mã, thích nghi các công nghệ nhập khẩu từ nước ngoài. Trên thực tế, nỗ lực công nghệ dựa trên tiếp cận công nghệ từ nước ngoài cho đến nay vẫn tỏ ra phù hợp với các nước đang phát triển đặt mục tiêu công nghiệp hóa và bắt kịp các nước đi trước.

Thư hai, các chính sách khuyến khích phát triển năng lực công nghệ dụa trên nền tảng kinh tế thị truoòng 
Ernst [4] cho rằng một hệ thống khuyến khích có lợi cho sự hình thành năng lực công nghệ nếu:

- Hạn chế được chiến lược tìm kiếm đặc lợi (rent-seeking $\left.{ }^{6}\right)$ của các chủ thể kinh tế và qua đó làm tăng thặng dư có thể đầu tư cho nền kinh tế (hướng đến xu thế profit-seeking theo quy luật thị trường);

- Bảo đảm rằng một tỷ lệ lớn các nguồn lực được đầu tư vào năng lực sản xuất và hình thành các năng lực công nghệ trong phạm vi lãnh thổ quốc gia;

- Dẫn dắt đầu tư vào các ngành công nghiệp và hướng tới xây dựng năng lực công nghệ, để trong tương lai năng lực của nền kinh tế có thể bảo đảm duy trì được mức lương cao cho người lao động; và

- Thực hiện được các hoạt động đầu tư dưới áp lực cạnh tranh quốc tế.

Theo các nguyên tắc này, một quốc gia đang phát triển khi thiết kế các chính sách khuyến khích, hỗ trợ cần phải tính đến các khía cạnh một mặt phải bảo đảm được sự bảo hộ các ngành công nghiệp dựa trên công nghệ mới nổi của quốc gia dựa trên các chính sách về thuế, tín dụng, hàng rào kỹ thuật và nghiên cứu triển khai, nâng cao năng lực, trình độ nhân lực,... Mặt khác cũng phải thiết lập được các chính sách tạo được động lực cạnh tranh trong nước và đặc biệt là hướng sự cạnh tranh đến các thị trường cao hơn ở nước ngoài thông qua các chính sách thương mại, FDI, nhập khẩu công nghệ, thiết bị từ nước ngoài,...Một cách ngắn gọn, hệ thống cách chính sách khuyến khích phát triển năng lực công nghệ công nghiệp cần phải được tạo lập để bảo đảm cho các doanh nghiệp công nghiệp trong nước khi triển khai các nỗ lực phát triển công nghệ có thể tiếp cận,

\footnotetext{
${ }^{6}$ Trong kinh tế học profit-seeking (tìm kiếm lợi nhuận tù̀ thị trường) và rent-seeking (trục lợi dựa trên quan hệ, nhóm lợi ích) là hai xu thế đối lập nhau. Một nền kinh tế có nhiều hoạt động rent-seeking sẽ làm méo mó các quan hệ thị trường và làm suy giảm khả năng cạnh tranh của nền kinh tế.
}

khai thác và sử dụng được nguồn nhân lực được đào tạo sã̃n có ở trong nước, nguồn tài chính và thông tin thị trường ở trong nước và quốc tế.

Thứ ba, hệ thống tổ chức hỗ trợ cho các hoạt động phát triển công nghệ.

Đối với các nước công nghiệp phát triển, việc duy trì một hệ thống hành chính giám sát và đôn đốc các hoạt động liên quan đến hoạt động công nghệ là không thực sự cần thiết do bản thân năng lực tự thân của các doanh nghiệp đã đủ lớn trên nhiều phương diện (quản trị doanh nghiệp, nghiên cứu, sáng tạo công nghệ, phát triển sản phẩm, tiếp thị, cạnh tranh quốc tế), đồng thời các nguyên tắc cốt lõi của thị trường tự do đã được định hình và vận hành hiệu quả. Ở chiều ngược lại, các nước đang phát triển lại thực sự cần có sự can thiệp và giám sát từ phía nhà nước do nền kinh tế chưa thể vận hành đầy đủ theo cơ chế thị trường, vẫn còn những thất bại (market failures) cần nhà nước chung tay chia sẻ rủi ro và quan trọng hơn là lực lượng doanh nghiệp vẫn còn yếu và thiếu kinh nghiệm trên nhiều phương diện. Do vậy, việc hình thành một cách có chủ ý và hệ thống các tổ chức hỗ trợ hoạt động phát triển công nghệ trong công nghiệp ở cấp độ quốc gia là rất quan trọng và không thể bỏ qua nếu muốn hướng đến các mục tiêu phát triển năng lực công nghệ và tự chủ công nghệ để cạnh tranh, bắt kịp các nước đi trước. Đây là bài học kinh nghiệm từ các nước công nghiệp mới (NICs) Đông Á. Không phải ngẫu nhiên mà trong suốt một thời gian dài, Bộ Công thương Nhật Bản (METI) lại là cơ quan đầu mối kiểm soát toàn bộ các hoạt động công nghiệp và phát triển công nghệ của quốc gia. Đi cùng với sự kiểm soát đó, việc hình thành Tập đoàn cho thuê Robot Nhật Bản (Japan Robot Leasing Corporation) như một biện pháp đẩy nhanh việc phổ biến công nghệ robot đến các doanh nghiệp vừa và nhỏ. Tại Hàn Quốc, không chỉ riêng việc thành lập Bộ Khoa học và Công nghệ từ những năm 1960, việc thành lập Viện KH\&CN Hàn Quốc, cơ quan giám sát chuyển giao công nghệ Hàn Quốc,... chính là những phương cách để Chính phủ Hàn Quốc có thể bảo đảm việc tập 
trung nguồn lực có trọng tâm, trọng điểm cho phát triển công nghệ trong cách ngành công nghiệp ưu tiên. Tại Đài Loan, việc thành lập Viện Công nghệ công nghiệp (ITRI), không thành lập cơ quan quản lý nhà nước về KH\&CN cũng là một phương án tổ chức đặc thù nhằm sớm chuyển hóa các thành quả KH\&CN bản địa để phục vụ các mục tiêu sản xuất công nghiệp hay tạo lập doanh nghiệp công nghệ mới đi tiên phong.

Tuy nhiên, vai trò và ảnh hưởng của các tổ chức dạng này không phải bất biến và luôn có hiệu quả cùng với thời gian mà phải luôn có sự điều chỉnh, thay đổi và cuối cùng là thu gọn lại khi mà nền kinh tế phát triển ở tầm cao mới, với năng lực công nghệ và khả năng cạnh tranh quốc tế ngày mạnh hơn so với các nước đi trước.

Thư tu, cấu trúc nền công nghiệp và lợ thế canh tranh

Nghiên cứu về khía cạnh kinh tế của chính sách phát triển công nghệ, Dasgupta [9] đã nhận định rằng việc xây dựng năng lực công nghệ, thông qua các nỗ lực nghiên cứu và phát triển không hẳn chỉ dựa vào các chính sách hỗ trợ của chính phủ, các tri thức công nghệ sẵn có mà còn liên quan đến cấu trúc công nghiệp, bởi vì các đặc trưng của từng ngành công nghiệp sẽ quyết định mức độ quan tâm và sử dụng công nghệ như thế nào.

Bell và Pavitt $[12,13]$ trong nghiên cứu về cấu trúc công nghiệp và khả năng nâng cao năng lực công nghệ đã nhận dạng được mỗi nhóm ngành công nghiệp sẽ có những đặc trưng và yêu cầu riêng đối với những nỗ lực nhằm phát triển năng lực công nghệ. Theo các nhà nghiên cứu này, trong công nghiệp có thể phân định thành 04 nhóm lớn gồm có:

+ Nhóm doanh nghiệp công nghiệp chịu sự chi phối của các nhà cung cấp (Supplier Dominated Firms) thuộc các ngành sản xuất truyền thống như nông nghiệp, dệt may, da giày, đồ gố,...

+ Nhóm doanh nghiệp công nghiệp phát triển theo quy mô (Scale - Intensive Firms) thuộc các ngành sản xuất công nghiệp nặng như luyện kim, thủy tinh, vật liệu bền, ô tô,...

+ Nhóm doanh nghiệp phát triển dựa vào khoa học (Science - Based Firms) thuộc các ngành điện, điện tử, hóa chất,...

+ Nhóm doanh nghiệp cung cấp các thiết bị chuyên dụng (Specialized -Supplier Firms) thuộc ngành sản xuất các phương tiện, công cụ sản xuất, phần mềm,....

Xem xét các ưu tiên công nghiệp của các nước công nghiệp mới (NICs) trong giai đoạn đẩy mạnh công nghiệp hóa (1960-1980) nhận thấy rằng các ngành công nghiệp dựa vào quy mô, hay còn gọi là các ngành công nghiệp nặng, công nghiệp xương sống, như luyện kim, đóng tàu, cùng với các ngành công nghiệp dựa vào khoa học như điện tử, viễn thông, chế tạo máy, hóa chất chính là những mũi nhọn được chính phủ các nước tập trung nguồn lực để phát triển nhất. Việc nâng cao vị thế cạnh tranh dựa trên năng lực công nghệ cũng xuất phát từ sự lựa chọn khôn ngoan đối với các ưu tiên lĩnh vực công nghiệp loại này.

Kinh nghiệm thực tiễn và những phân tích của Bell và Pavitt $[12,13]$ đã cho thấy cấu trúc các ngành công nghiệp trong một quốc gia, dù có thể thông qua ưu tiên của chính phủ hay có tính chất truyền thống lâu đời, thực sự có ảnh hưởng rất lớn đối với các nỗ lực phát triển năng lực công nghệ cũng như là khả năng cạnh tranh quốc gia. Với các nước đang phát triển, khi mà xuất phát điểm luôn từ các ngành công nghiệp chịu sự chi phối của nhà cung cấp như nông nghiệp, dệt may, da giày,...thì việc lựa chọn khôn ngoan các ưu tiên phát triển công nghiệp sẽ bảo đảm cho các nỗ lực công nghệ của quốc gia sẽ được triển khai một cách hiệu quả và thuận lợi hơn.

Tuy nhiên, trên thực tế ở nhiều quốc gia đang phát triển, không phải lúc nào cũng có điều kiện để lựa chọn và tập trung nguồn lực để phát triển một ngành công nghiệp mới, dù rằng ngành đó rất quan trọng và có tiềm năng cạnh tranh cao. Nhật Bản đã thành công với việc khởi tạo ngành công nghiệp điện tử, bán dẫn, Hàn Quốc đã đạt được vị thế cạnh tranh quan 
trọng trên thế giới khi ưu tiên cho ngành thép, đóng tàu nhưng Hongkong, Malaysia hay Indonesia cũng đạt được những thành tựu phát triển và công nghiệp hóa quan trọng không phải dựa vào các ngành công nghiệp ở trên mà dựa vào các ngành rất truyền thống là nông nghiệp, dệt may hay đồ chơi trẻ em. Sự thành công của các quốc gia này (Hongkong, Malaysia, Indonesia,...) dựa trên khả năng nắm bắt những yếu tố khác, liên quan đến lợi thế cạnh tranh quốc gia.

Như vậy có thể thấy rằng, nhân tố cấu trúc công nghiệp và lợi thế cạnh tranh có ảnh hưởng đáng kể đến các nỗ lực phát triển năng lực công nghệ. Tùy theo cấu trúc của nền công nghiệp quốc gia, thông qua các đặc trưng công nghiệp hoặc lợi thế cạnh tranh quốc gia, có thể dẫn đển các phương cách ứng xử và can thiệp khác nhau đối với quá trình xây dựng năng lực công nghệ.

\section{Một số gợi mở để phát triển năng lực công nghệ ở Việt Nam}

Phân tích ở trên đã cho thấy rằng để tạo lập được vị thế cạnh tranh trong các lĩnh vực sản xuất công nghiệp cần thiết phải dựa trên năng lực công nghệ. Các nghiên cứu đã chỉ ra rằng năng lực công nghệ trong ngành công nghiệp hay ở cấp độ quốc gia được hình thành thông qua quá trình học hỏi, tích lũy tri thức, kinh nghiệm, kỹ năng về công nghệ thông qua hoạt động sản xuất, nghiên cứu và phát triển,...Quá trình tạo lập năng lực công nghệ cơ bản xuất phát từ các nỗ lực của doanh nghiệp và có sự lan tỏa để nâng cấp lên ở cấp độ ngành và quốc gia.

Nỗ lực xây dựng năng lực công nghệ ở các quốc gia đang phát triển luôn gặp nhiều khó khăn hơn các nước công nghiệp phát triển. Nghiên cứu về các nước đang phát triển đã cho thấy do sự kém phát triển về các thiết chế thị trường, sự bất đối xứng trong tiếp nhận thông tin về thị trường hàng hóa, công nghệ,...nên cách thức tạo lập năng lực công nghệ ở các nước đang phát triển sẽ không thể tương tự như các nước đi trước, đã phát triển tương đối toàn diện về thị trường và thiết chế. Trong bối cảnh như vậy, sẽ không thể có sự "giao phó" hoàn toàn việc thúc đẩy năng lực công nghệ dựa vào các cơ chế của thị trường tự do mà thay vào đó sự can thiệp bằng các công cụ chính sách của chính phủ trong các nỗ lực phát triển năng lực công nghệ là cần thiết, bảo đảm có đủ động lực và nguồn lực để bắt kịp các nước đi trước trên một số lĩnh vực.

Thực tiễn về quá trình tạo lập và phát triển năng lực công nghệ của các nước Đông Á trong quá trình thực hiện công nghiệp hóa những năm 1970 đã cho thấy các quốc gia này đã rất chủ động trong việc xác lập các ưu tiên công nghiệp để từ đó làm cơ sở phát triển năng lực công nghệ bám sát các yêu cầu về công nghiệp đã đặt ra. Bên cạnh đó, thay vì hướng đến các nỗ lực phát triển năng lực nghiên cứu cơ bản và hệ thống nghiên cứu - triển khai nội tại để cạnh tranh với các nước công nghiệp phát triển, chính phủ các nước Đông Á lại dành ưu tiên nguồn lực cho các nỗ lực phát triển năng lực công nghệ trong các doanh nghiệp công nghiệp thông qua các hỗ trợ để tiếp cận công nghệ mới, công nghệ tiên tiến từ nước ngoài kết hợp với các phương thức bảo hộ phù hợp với sản phẩm, công nghệ được tạo ra từ trong nước. Dựa trên các nỗ lực chính sách khôn ngoan của chính phủ và sự bền bỉ, quyết tâm học hỏi công nghệ của các doanh nghiệp, vị thế và năng lực công nghệ ở các quốc gia này đã dần được tích lũy và nâng cao, từng bước cạnh tranh và chiếm lĩnh được thị trường quốc tế trên nhiều lĩnh vực công nghiệp.

Đối với Việt Nam, mục tiêu đẩy nhanh quá trình công nghiệp hóa đất nước cũng đã được đề cập trong nhiều văn kiện của Đảng và Nhà nước trong thời gian dài. Nhà nước cũng đã tập trung nguồn lực để thực hiện các mục tiêu phát triển công nghiệp cũng như là tạo lập năng lực cạnh tranh công nghiệp dựa trên công nghệ. Tuy nhiên, cũng có thể nhận thấy, định hướng công nghiệp hóa của Việt Nam chưa nhất quán và rành mạch trong việc xác định các ưu tiên công nghiệp để có thể tập trung nguồn lực theo đuổi đến cùng. Chính vì lý do này nên dù trong những thập niên vừa qua, nền kinh tế có những bước tăng trưởng tích cực nhưng chất lượng 
tăng trưởng còn chưa cao. Nếu so với các sách lược mà các nước Đông Á đã thực hiện như nêu ở trên thì Việt Nam ở trạng thái đã có tính đến, đã có hoạch định nhưng việc thực thi và kết quả cuối cùng lại không tích cực như các nước đi trước.

Tuy nhiên, nếu nhìn vào những khía cạnh bản chất của phát triển năng lực công nghệ như đã trình bày ở trên, cũng như những trải nghiệm hữu ích của các quốc gia Đông Á đã được mô tả trong nhiều nghiên cứu liên quan, có thể nhận thấy vẫn còn có những vấn đề chính sách cần được xem xét, bổ sung trong lộ trình hoạch định chính sách công nghệ thời gian tới ở Việt Nam. Các gợi mở có thể xem xét như sau:

Thứ nhất, bên cạnh những quan tâm, đầu tư cho hoạt động nghiên cứu - triển khai từ khu vực viện - trường, cần có những hành lang để hỗ trợ, đầu tư cho hoạt động phát triển công nghệ của khu vực doanh nghiệp (bao gồm cả hoạt động tiếp nhận, nghiên cứu, làm chủ công nghệ từ nước ngoài). Trên thực tế, các doanh nghiệp có thể chưa đủ nguồn lực để thực hiện các hoạt động nghiên cứu - phát triển còn chứa đựng nhiều rủi ro, nhưng luôn có nhu cầu và mục tiêu trong việc tiếp cận các công nghệ hoặc thiết bị sẵn có, đủ tin cậy từ nước ngoài. Khi công nghệ được nhập về, người sử dụng công nghệ sẽ thường ưu tiên khai thác các lợi ích kinh tế, ít xem xét đến việc khai thác, học hỏi các tri thức tiềm ẩn phía sau. Như thế, về lâu dài các ngành sản xuất ở Việt Nam sẽ chỉ là những người "sử dụng công nghệ, thiết bị" thuần thục, sẽ chịu lệ thuộc vào các quốc gia hay tổ chức cung cấp công nghệ gốc. Do vậy, điểm cần quan tâm thay đổi là cần có thêm những hỗ trợ hoặc khuyến khích từ nhà nước, các doanh nghiệp và nhà khoa học sẽ có cơ hội để khai thác, tìm hiểu các giá trị về tri thức gắn kèm với công nghệ được chuyển giao theo lộ trình dài hạn hơn. Theo quan điểm này, việc hình thành một chương trình nghiên cứu, giải mã công nghệ theo một số nhóm ngành sản phẩm hoặc công nghiệp Việt Nam có lợi thế cần được đưa vào lộ trình xây dựng chính sách ở cấp quốc gia hoặc cấp địa phương. Khi chương trình theo hướng tiếp cận này được triển khai sẽ mở ra cơ hội cho không chỉ các doanh nghiệp mà cho cả lực lượng các nhà khoa học trong nước và từ nước ngoài tham gia vào các hoạt động này.

Thứ hai, việc đầu tư của xã hội và nhà nước cho hoạt động phát triển công nghệ cần phải có trợng tâm, trong điểm. Các nước Đông Á trong nồ lực nhập khẩu, nghiên cứu làm chủ công nghệ cũng có những ưu tiên nhất định. Nhật Bản, Hàn Quốc ưu tiên cho công nghiệp điện tử, ô tô trong khi Đài Loan lại tập trung vào công nghiệp bán dẫn. Dựa trên những ưu tiên công nghiệp này, các quốc gia đã xác định những hướng đi phù hợp cùng với nguồn lực tài chính được bảo đảm để thực hiện đến cùng sứ mệnh từ mô phỏng, bắt chước đến làm chủ, sáng tạo công nghệ trong ngành công nghiệp đó. Để thúc đẩy công nghiệp hóa, Việt Nam đã xác định nhiều ưu tiên công nghiệp trong các lĩnh vực khác nhau, tuy nhiên trên phương diện khoa học và công nghệ rất cần xác định được các ưu tiên công nghiệp đặc thù, là xương sống của nền kinh tế để làm cơ sở cho phát triển năng lực công nghệ vươn tới khả năng cạnh tranh được với quốc tế. Sự lớn mạnh của một lĩnh vực công nghiệp trên trường quốc tế sẽ tạo được hiệu ứng lan tỏa sang các ngành khác.

Thứ ba, cùng với những nỗ lực phát triển công nghệ, yếu tố nhân lực để có thể tiếp nhận, hấp thu các tri thức công nghệ mới cũng rất cần được quan tâm. Kinh nghiệm các nước Đông Á đã cho thấy dựa trên việc tạo lập được lực lượng nhân lực trình độ cao trong các lĩnh vực khoa học tự nhiên và kỹ thuật thông qua đào tạo trong nước và thu hút từ nước ngoài mà các ngành sản xuất công nghiệp được hưởng lợi vì đã khai thác được tối đa hiệu suất công nghệ nhập, và đồng thời có thể tiến tới làm chủ, sáng tạo công nghệ mới với chi phí thấp hơn. Một cách trực tiếp đã tạo được năng lực cạnh tranh dựa trên công nghệ cho các doanh nghiệp trong nước. Khuyến nghị cần xem xét là cần thiết lập các chương trình nghiên cứu hoặc học bổng nghiên cứu trong một số lĩnh vực khoa học tự nhiên và kỹ thuật (tương tự như các nước Tây Âu đang áp dụng) để thu hút các nhà khoa học, các kỹ sư theo đuổi các nghiên cứu chuyên sâu 
về công nghệ ở trình độ cao hơn. Các lĩnh vực nghiên cứu này cần phải gắn với các nhu cầu sản xuất công nghiệp từ khu vực doanh nghiệp. Đồng thời, cũng cần phải thay đổi chế độ tuyển dụng, sử dụng và đãi ngộ đối với lực lượng nghiên cứu có trình độ từ nước ngoài đến làm việc ở Việt Nam.

Thứ tư, cùng với những nỗ lực để phát triển năng lực công nghệ để làm nền tảng nâng cao năng suất, chất lượng của sản phẩm, hàng hóa trong nước, việc tạo lập các lợi thế cạnh tranh cũng rất quan trọng. Các chính sách về mua sắm công, các cơ chế thiết lập hàng rào kỹ thuật trong nước cũng cần phải được xem xét và thiết kế đồng bộ với những nỗ lực phát triển năng lực công nghệ trong các ngành công nghiệp, lĩnh vực sản xuất được ưu tiên quốc gia.

\section{Tài liệu tham khảo}

[1] Enos, The Creation of Technological Capability in Developing countries. Pinter Publishers, London, 1991.

[2] Sharif, Strategic Role of Technological SelfReliance in Development Management, Technological Forecasting and Social Change, 62, 1999, 219-238.

[3] Lall, S. Technological capabilities and industrialisation. World Development, 20 (2) , 1992, 165-186.

[4] Ernst và cs, Technological Capability and Export Success in Asia, Routledge, London, 1998.

[5] Aderemi và cs, Development of a Measurement for technological capability in the Information and
Communications Technology Industry in Nigeria, 1999.

[6] Litan, Nghịch lý của chiến lược bắt kịp: Tư duy lại mô hình phát triển kinh tế dựa vào nhà nước, NXB Trẻ, 2005.

[7] Lall, Technological Change and Industrialization in the Newly Industrializing Economies: Achievements and Challenges, Chapter 2. In: Kim and Nelson (Ed.). Technology, Learning and Innovation: Experiences of Newly Industrializing Economies. Cambridge University Press, London, 2000.

[8] Kim, Building Technological Capability for Industrialization: Analytical Frameworks and Korea Experience. Industrial and Corporate Change 8 No. 1, 1999, 111-136

[9] Dasgupta và cs, Economic policy and technological performance, Cambridge University Press, 1987.

[10] Lall, Reinventing Industrial Strategy: The role of Government Policy in Building Industrial Competitiveness, UN, 2004.

[11] Westphal và cs, Reflections on Korea's Acquisition of Technological Capability, WB, 1984.

[12] Bell và Pavitt, Accumulating Technological Capability in Developing Countries, Proceedings of the World Bank Annual Conference on Development Economics, 1993.

[13] Bell và Pavitt, The development of technological capabilities; Chapter 4 in Haque, Ed., Trade, Technology, and international competitiveness, Economic Development Studies, The World Bank, Washington, DC, 1995.

[14] Kiheung Kim, Technology Tranfer: the case of the Korean Electronic Industry, IEEE, 1998. 


\title{
Some Implications for Technological Capability Development in Vietnam
}

\author{
Nguyen Hoang Hai \\ State Agency for Technology Innovation, SATI, 113 Tran Duy Hung, Hanoi, Vietnam
}

\begin{abstract}
Technological capacity is considered as the most important factor in the process of promoting economic development and catching up with industrialized countries. For this reason, the governments of many developing countries have constantly made their attempts to find measures to promote the development of technology capacity. The experience in technological capacity development in East Asian countries during the process of promoting the industrialization has brought many valuable lessons for other countries. Based on the experience from East Asian countries, this article provides additional insights into the nature and conditions of technological capacity development for developing countries like Vietnam, trying to catch up with the leading industrialized countries.
\end{abstract}

Keywords: Technology, technological capability, development of technological capability, policy for development of technological capability. 